\title{
Consejo General del Poder Judicial y política de la justi- cia en España ${ }^{1}$
}

Luis López Guerra

\section{El gobierno del Poder Judicial}

La Constitución española, en su Art. 122․2, define al Consejo General del Poder Judicial como «órgano de gobierno» de ese poder. Los años transcurridos desde la aprobación de la Constitución han podido mostrar las dificultades que surgen a la hora de definir (en la doctrina, en la legislación y en la jurisprudencia) qué debe entenderse por «gobierno del poder judicial». A los problemas bien conocidos que se presentan para precisar el mismo concepto de gobierno, o, si se quiere, de la función de gobierno, vienen a unirse los que derivan de la aplicación de ese concepto a un poder integrado por jueces y magistrados que la Constitución adjetiva como independientes y sujetos únicamente al imperio de la ley.

De manera inicial, las dudas y discusiones que han surgido a este respecto pudieran clasificarse en dos apartados. Por un lado, cuál puede ser el contenido de esa función de gobierno, esto es, qué potestades y competencias incluye; por otro, y con no menor relevancia, cuál debe ser el régimen de ejercicio de esas potestades y competencias. Es decir, del grado de libertad de que dispone el Consejo en su ejercicio de los controles a que está sujeto. Como se tratará de exponer a continuación, las respuestas a estas cuestiones, íntimamente relacionadas entre sí, no han sido ni pacíficas en la doctrina, ni invariables en la práctica.

1 El presente artículo fue escrito como contribución al libro-homenaje al profesor D. Francisco Rubio Llorente. 
La determinación del primer aspecto se ve dificultada porque la atribución al Consejo General del Poder Judicial del gobierno del mismo no viene acompañada, en la Constitución, de una enumeración tasada de las materias sobre las que debe versar ese gobierno. El Art. 1220.2 $\mathrm{CE}$ se remite a "la ley orgánica" para el establecimiento de las funciones del Consejo, con una fórmula abierta, a partir de unos mínimos indisponibles: «en particular en materia de nombramientos, ascensos, inspección y régimen disciplinarion. Esta remisión ha dado lugar a regulaciones muy diversas, que han ampliado y restringido sucesivamente las competencias del Consejo. Desde luego la interpretación que se ha dado a la expresión "gobierno del poder judicial» no se ha traducido en ningún caso en la traslación al Consejo de la totalidad (o la mayor parte) de las funciones relativas a la administración de justicia que tradicionalmente había venido ejerciendo el poder ejecutivo, y particularmente el Ministerio de Justicia. En este sentido, el Consejo dista con mucho de disponer de poderes de gobierno de la justicia similar a los que pertenecen por atribución constitucional a las cortes supremas de algunas repúblicas latinoamericanas, carentes en algún caso, del mismo Ministerio de Justicia. ${ }^{2}$

Como es bien sabido, en la tradición española, las funciones de gobierno del poder judicial han correspondido, bien a los mismos órganos jurisdiccionales (por medio de instituciones como los jueces decanos, salas de gobierno, o presidentes de sala, instituciones a que se hace una referencia oblicua en el Art. 122 $.1 \mathrm{CE}$, al mencionar al "gobierno de juzgados y tribunales»), bien, y sobre todo, al Ministerio de Justicia. ${ }^{3} \mathrm{La}$ presencia de éste se ha mantenido, tras la Constitución de 1978, como factor determinante en la organización general de la administración de justicia. Ciertamente, no existe (como sí es el caso en la Constitución italiana, en su artículo $110^{\circ}$ ) una constitucionalización del Ministerio de Justicia como órgano con tareas propias. Pero ello no obsta a su relevante presencia en la realidad, y a que legalmente se le encomienden tareas que bien pudieran considerarse incluidas, directa o indirectamente, en la función de "gobierno" del poder judicial.

$2 \mathrm{Me}$ remito, en este aspecto, a mi trabajo "Modelos de gobierno de los jueces" incluido en El poder judicial en el Estado constitucional, Lima, 2001.

3 Una completa exposición histórica puede encontrarse en M.A. Aparicio, El status del poder judicial en el constitucionalismo español (1808-1936), Barcelona, 1995. 
Precisamente, la delimitación entre las competencias del poder ejecutivo y del Consejo General del Poder Judicial a este respecto ha estado sujeta a notables cambios en los primeros veintidós años del actual régimen constitucional. Las diversas regulaciones sobre la materia que se han producido hasta el momento (la correspondiente a la LO 1/1980 del Consejo General del Poder Judicial, la LOPJ de 1985 y las reformas de ésta en 1994 y 2000) han venido a contener fórmulas distintas de reparto de competencias entre Consejo y Ministerio en lo referente al contenido de esa función de gobierno.

La primera regulación post-constitucional al respecto, la Ley Orgánica de 1980 del Consejo General del Poder Judicial confería al CGPJ potestades muy amplias, o al menos bastante más amplias de las que hoy dispone. Debe destacarse que entre ellas, aparte del núcleo mínimo garantizado en la Constitución, se incluía un amplio reconocimiento de la potestad reglamentaria del Consejo, así como competencias relativas a la selección y formación inicial de jueces, al régimen retributivo de los jueces, magistrados, y personal de la administración de justicia; y, en general, todas las competencias concernientes a secretarios de justicia, así como respecto del personal auxiliar y colaborador de la administración de justicia. Le atribuía también poderes (indefinidos) de iniciativa y propuesta legislativas, $y$, más precisamente, de informe sobre proyectos de ley en materias relacionadas con la administración de justicia.

La posterior Ley Orgánica del Poder Judicial de 1985 supuso que el Consejo perdiera gran parte de las competencias arriba enumeradas, quedando sus potestades prácticamente reducidas a las listadas en el Art. $122^{\circ} .2 \mathrm{CE}$. El Consejo perdió las competencias relativas a selección de jueces, así como la gestión de la Escuela judicial; vio drásticamente reducida su capacidad reglamentaria, y eliminadas sus competencias sobre secretarios de justicia, personal administrativo, y sobre lo concerniente al régimen retributivo de jueces, magistrados, y personal de justicia. Desapareció también en la ley toda referencia a su capacidad de propuesta legislativa, y la de informe se restringió a los anteproyectos de ley. ${ }^{4}$

4 Ver, sobre los cambios de 1985, C. Fernández-Miranda Campoamor «El Consejo General del Poder Judicial: de la L.O. $1 / 1980$ de 10 de enero a la L.O. 6/1985 de 29 de julio" en Revista de Derecho Político 38 (1993) pp. 37-92. Para una exposición general, M. J. Terol Becerra, El Consejo General del Poder Judicial, Madrid, 1990. 
En este movimiento de vaivén la reforma de la LOPJ de 1994 supuso un nuevo cambio, esta vez, en general, en sentido ampliatorio de las potestades del Consejo. Éste recuperó sus competencias en materia de selección y de Escuela judicial, y vio aumentada su potestad reglamentaria; igualmente, se le confirió autonomía presupuestaria respecto del gobierno, al encomendársele la redacción del proyecto de su propio presupuesto. Así y todo perdió alguna competencia (como en cuanto al horario de la oficina judicial). Pero el resultado de reforma fue, considerado globalmente, muy favorable a las competencias del Consejo. ${ }^{5}$

En los años posteriores no faltaron (desde el ámbito del mismo Consejo) propuestas para una mayor ampliación, contenidas tanto en el Libro Blanco de la justicia de 1997, como en las Propuestas para una Reforma de la justicia de 2000. ${ }^{6}$ No obstante, la reforma de la Ley Orgánica del Poder Judicial de ese año (LO 9/2000, de 22 de diciembre) vino a suponer una reducción competencial del Consejo, al encomendarse el proceso de selección de jueces conjuntamente a éste y al Ministerio de Justicia, como resultado de la incorporación a ese proceso del cuerpo de fiscales.

Resultado de todo ello es una compleja distribución de competencias de gobierno entre órganos jurisdiccionales, CGPJ y poder ejecutivo: con la complicación añadida de que la estructuración autonómica del Estado ha dado lugar (debido a las llamadas cláusulas subrogatorias de los Estatutos de Autonomía y su interpretación por la jurisprudencia constitucional) a que competencias atribuidas al Ejecutivo hayan

5 Para un comentario sobre la reforma de 1994, aun en su fase de tramitación parlamentaria, V. Cortés Domínguez, «Naturaleza del Consejo General del Poder Judicial» en G. Pedraz Penalva (Coordinador) El Gobierno de la Justicia. El Consejo General del Poder Judicial, Valladolid, 1996, pp. 173-180. Para lo que atañe a la reforma de la potestad reglamentaria del CGPJ, J.M. Porras Ramírez, "Fundamento, naturaleza, extensión y límites de la potestad reglamentaria del Consejo General del Poder Judicial» En: Revista de Estudios Políticos 87 (1995) pp. 239-257.

6 Libro Blanco de la Justicia, publicado por el Consejo General del Poder Judicial, Madrid, 1997. Para las propuestas del año 2000, "Propuestas del Consejo General del Poder Judicial para la reforma de la Justicia. Sobre la base del Libro Blanco y de las Sugerencias formuladas por las Salas de Gobierno», en Del modo de arreglar la justicia. Informes y propuestas para la mejora de la justicia elaborados por el Consejo General del Poder Judicial, Tribunal Supremo, Audiencia Nacional y Tribunales Superiores de Justicia de las Comunidades Autónomas. Madrid, 2000, pp. 1-87. 
sido asumidas por los gobiernos de las respectivas Comunidades Autónomas, de manera que las Consejerías de Justicia autonómicas comparten competencias con el Ministerio de Justicia. ${ }^{7}$

No resulta fácil por ello reducir a una unidad sistemática los criterios que definen en la actualidad aquello que la ley considera como el contenido del gobierno del poder judicial: sólo la referencia a los listados legales permite determinar qué competencias en materia de administración de justicia pertenecen a qué sujetos. En líneas generales, forzosamente aproximativas, cabría decir que el núcleo de las competencias del Consejo se refieren al cuerpo único de jueces y magistrados (nombramientos, formación inicial y continuada, inspección, disciplinaria, ascensos y traslados, jubilación, licencias y permisos) si bien éste carece de competencias en lo referente a presupuestos, retribuciones y mutualismo del personal judicial, y debe compartir con el Ministerio de Justicia la potestad de selección. A este núcleo inicial se une un conjunto heterogéneo de facultades referentes a materias instrumentales (informática, reglamentos de índole interna) y de cooperación con otros poderes, esencialmente la formulación de informes (a anteproyectos de ley, al nombramiento de Fiscal General, a materias de demarcación y planta judicial) y la propuesta de dos magistrados del Tribunal Constitucional.

Este conjunto de poderes se ve forzosamente relativizado si se compara con los correspondientes al poder ejecutivo, que dispone de una amplia serie de potestades en materia de justicia, potestades que necesariamente repercuten, en forma más o menos directa, en el gobierno judicial. Resulta decisivo, al respecto el poder sobre la bolsa, ya que corresponde al Gobierno establecer, en el proyecto de ley de presupuestos, los relativos a la justicia, incluyendo la partida destinada a retribuciones judiciales. ${ }^{8}$ Es también competencia del ejecutivo (del estatal, o de los ejecutivos autonómicos) todo lo referente a la gestión de medios materiales y personales de la administración de justicia. El "gobierno del poder judicial», pues, atribuido al CGPJ por la Constitución se configura, en la experiencia constitucional de estos años, como

7 Sobre este tema, R. Jiménez Asensio, Dos estudios sobre Administración de Justicia y Comunidades Autónomas, Madrid, 1998.

8 Como ejemplo, en el BOE de 29 de diciembre de 2000 se publicaban las partidas del Presupuesto para el año 2001 correspondientes al Ministerio de Justicia (171.787 millones) y al Consejo General del Poder Judicial (7.649 millones). La diferencia es notoria. 
un conjunto de funciones de entidad reducida (al menos cuantitativamente) en el marco de la administración de justicia.

\section{Funciones administrativas y funciones políticas del CGPJ}

En general se admite que la finalidad y justificación del CGPJ reside en la garantía de la independencia de jueces y tribunales, fundamentalmente frente al poder ejecutivo.? Ahora bien, para ponderar adecuadamente la importancia, eficacia y formas de manifestarse de esta garantía, es necesario tener en cuenta que esa independencia se ve asegurada además, en el texto constitucional, por muchos otros medios: cabría considerar incluso que en realidad, la existencia del CGPJ es una garantía añadida. Esta consideración se justifica aún más si se tiene en cuenta que, en Derecho comparado, no hay una absoluta equivalencia entre la garantía de la independencia judicial y la existencia de un órgano autónomo de gobierno del poder judicial. ${ }^{10}$

Los ejemplos de técnicas constitucionales de garantía de la independencia de jueces y magistrados, separadas y distintas de la existencia del CGPJ son muy variados; sin necesidad de mayores exposiciones, valga señalar la reserva general de ley orgánica en relación con el estatuto de jueces y magistrados (Art. $122^{\circ} \mathrm{CE}$ ), lo que les blinda, por así decirlo, de la acción del ejecutivo; el establecimiento de un sistema de carrera de jueces y magistrados (Art. 122 .1 CE) que, unido a la garantía de la inamovilidad (Art. $177^{\circ} .1 \mathrm{CE}$ ) excluye la posibilidad de remociones discrecionales. Y, más allá de la garantía de inamovilidad, la independencia se ve además reforzada por el sistema de incompatibilidades y prohibiciones del Art. $127^{\circ} \mathrm{CE}$. Y, aparte de estas previsiones específicas, la posición de juez en cuanto funcionario público se

9 Ver, por ejemplo, J.F. López Aguilar, La Justicia y sus problemas en la Constitución, Madrid, 1996, pp. 114-118; también, P. Cachón Villar, "La ubicación del Poder Judicial entre los poderes del Estado", en el volumen Escuela de Verano del Poder Judicial 1998. Madrid, 1999, pp. 327-380, especialmente pp. 357-358.

10 Para una visión comparada son útiles los trabajos contenidos en los volúmenes The role of the Judicial Service Commission, Estrasburgo, 1995, y Les Conseils supérieus de la Magistrature en Europe, París, 1999, dirigido por Thierry S. Renoux. En castellano, P. Lucas Murillo, «El gobierno del poder judicial: los modelos y el caso español" En: Revista de las Cortes Generales, 35 (1995) pp. 167-239. 
ve protegida por las disposiciones constitucionales que velan por los derechos de éstos frente a actuaciones arbitrarias o ilegales por parte de los órganos de gobierno del poder judicial. La Constitución, pues, y en un nivel inferior la ley establece una batería de garantías que buscan eliminar aquellas vías de influencia que tradicionalmente habían amenazado la independencia judicial.

Todo ello supone que el régimen de jueces y magistrados (todo lo referente a ingreso en la carrera, ascensos, traslados, licencias y permisos, jubilación, inspección, sanciones y cuestiones similares) se encuentra detenidamente regulado en la ley, de manera que en estos aspectos el órgano de gobierno de los jueces no dispone de un ámbito de actuación discrecional, sino que se encuentra esencialmente en la posición de un mero ejecutor o administrador, sometido además al control judicial que deriva de lo previsto en el Art. 106 $.1 \mathrm{CE}$. Desde esta perspectiva, el hecho de que esa tarea ejecutiva o administrativa se encomiende al Consejo General del Poder Judicial, y no al poder ejecutivo (Ministerio de Justicia) no deja de tener más que una importancia relativa. Si las disposiciones legales son lo suficientemente adecuadas y el control judicial lo adecuadamente efectivo, la identidad del órgano ejecutor queda en un segundo plano, y no parece que el mantenimiento de la fórmula tradicional que atribuía esa ejecución al Ministerio de Justicia fuera per se contraria a la separación de poderes y a la independencia judicial. Otra cosa es, desde luego, que, sobre la base de una saludable desconfianza hacia el Gobierno, se prefiera encomendar tal ejecución a un órgano separado de éste, como garantía, si no imprescindible, sí conveniente. ${ }^{11}$

Lo que ocurre -y que justifica la existencia del CGPJ como órgano necesario y no meramente conveniente- es que, aparte de estas funciones administrativas o ejecutivas, hay un conjunto de actuaciones de dirección y gestión, relativas tanto a la posición de jueces y magistrados concretos como al conjunto orgánico que integra el poder judicial, que no pueden considerarse como de mera ejecución de preceptos legales,

11 En términos de la STC 108/86 "Las funciones que obligadamente ha de asumir el Consejo son aquellas que más pueden servir al Gobierno para intentar influir sobre los Tribunales: de un lado, el posible favorecimiento de algunos jueces por medio de nombramientos y ascensos; de otra parte, las eventuales molestias y perjuicios que podrían sufrir con la inspección y la imposición de sanciones». 
ni resultan estrictamente controlables y revisables en su integridad por la jurisdicción contencioso administrativa. El gobierno del poder judicial comprende también actuaciones que no están ni pueden estar predeterminadas por la ley, sino que exigen un cierto margen de libertad para apreciar las circunstancias del momento, y para elegir entre las diversas alternativas presentes. De la misma forma que hay una actividad "de gobierno" referida al conjunto de las instituciones (como se recoge en el Art. $97^{\circ} \mathrm{CE}$, al prever la función de dirección política) es ineludible también la presencia de una actividad de gobierno en relación con el poder judicial, que supongan una dirección política en su más puro sentido. En esta limitada acepción, cabe hablar de una "política judicial», es decir de aquellas actuaciones relativas al poder judicial en que la Constitución y la ley dejan un amplio margen de apreciación a su órgano de gobierno.

Conviene llevar a cabo en este punto una precisión. Es evidente que "política judicial» no equivale a "política de la justicia». Este último término se refiere a un aspecto más amplio de la vida pública, y comprende todas aquellas actuaciones de los diversos poderes del Estado que se refieren a la administración de justicia en su conjunto como servicio público, es decir, tanto al establecimiento del marco legal en que se desarrolla el ejercicio de la función jurisdiccional, como a la provisión de los medios con que debe contar para que pueda prestar una tutela judicial efectiva según lo dispuesto en el Art. 240.1 CE. Se trata así de una tarea con múltiples manifestaciones, que incluye la elaboración de la correspondiente legislación procesal, la provisión de medios materiales y personales, y las líneas generales de la gestión de todos ellos. Es evidente que la formulación de esa "política de la justicia» debe corresponder a los sujetos de la dirección política general, esto es, al gobierno, y, a iniciativa de éste, a las Cortes. En un plano distinto, la «política judicial» que corresponde al CGPJ tiene un ámbito más reducido, ya que se refiere únicamente al poder judicial como conjunto orgánico integrado por jueces y magistrados, de acuerdo con el Art. $117^{\circ} .1 \mathrm{CE}$.

Otra cosa es, desde luego, determinar el alcance de esa política judicial. Ya se vio que la división de funciones entre CGPJ y Ministerio de Justicia (o, en general, entre CGPJ y poder ejecutivo, estatal o autonómico) resulta difícil de reducir a criterios sistemáticos. Si se parte de que la justificación última del Consejo General del Poder Judicial reside en la garantía de la independencia judicial, cabría concluir que, a la vista de lo dispuesto en el artículo $122^{\circ} \mathrm{CE}$ deben corresponder al Consejo (y 
no al poder ejecutivo) todas aquellas potestades, administrativas o políticas, relacionadas directa o indirectamente con el "gobierno de los jueces" y que puedan incidir en la independencia de éstos. Ello implica, por un lado, el ejercicio de funciones administrativas o ejecutivas de carácter reglado, que, por su especial relevancia en el status del juez resulte conveniente excluir de la esfera de su titular tradicional, el poder ejecutivo; pero también, y sobre todo, las previsiones constitucionales exigen que se atribuya al Consejo ( $y$ tal es hoy en caso) un conjunto de facultades que, en el sentido arriba apuntado, cabe calificar como políticas, facultades que no dejan de plantear serios problemas (de lege lata y de lege ferenda) referentes tanto a su propia extensión cuanto a la forma, límites y control de su ejercicio.

\section{Las funciones políticas del CGPJ. El caso de los nombramientos}

No resulta difícil encontrar ejemplos de estas decisiones políticas del CGPJ, en el sentido de decisiones adoptadas libremente (dentro de un muy amplio marco legal) de entre una pluralidad de posibilidades, todas ellas legítimas. Como muestra valga citar algunas de las adoptadas en la primera sesión "operativa" del Consejo elegido en julio de 1996. Entre ellas figuran la ratificación del acuerdo de la comisión permanente, relativo al contenido del programa de oposiciones a la carrera judicial; la ratificación del acuerdo del mismo órgano por el que se ubicaba en la ciudad de San Sebastián el Centro de Documentación del Consejo General del Poder Judicial; la ratificación del acuerdo, también de la comisión permanente, relativo a la cuantía y distribución de subvenciones a las asociaciones judiciales, por una cuantía de 56 millones y medio de pesetas; $y$, finalmente, en esta enumeración ejemplificativa, la ratificación de acuerdos relativos a gastos en materia de formación y publicaciones. Como puede verse se trata de decisiones que suponían elegir entre opciones abiertas; mantener o cambiar el temario de oposiciones, seleccionar la sede del Centro de Documentación, o establecer la cuantía destinada a apoyar a las asociaciones judiciales y su distribución. ${ }^{12}$

12 Una referencia a estos acuerdos puede encontrarse en Pleno. Acuerdos del Pleno del CGPJ. 1996 (II). Madrid, 1996, p. 27 y ss. correspondientes al Pleno de 31 de julio de 1996. 
En todas ellas la apreciación subjetiva por el Consejo de la conveniencia u oportunidad de esas medidas, de entre las alternativas posibles, fue el motivo y justificación de su adopción.

Posiblemente el ejemplo más destacado (y el que suele atraer con cierta frecuencia la atención de la opinión pública) del ejercicio de funciones políticas por parte del Consejo General del Poder judicial sea el referido a los nombramientos discrecionales de los titulares de determinados órganos jurisdiccionales. Se trata de un número restringido en relación con lo que pudieran denominarse nombramientos «reglados»; pero versan sobre aquellos puestos que ostentan mayor relevancia en la imagen pública de la judicatura.

El artículo $122^{\circ} .1$ de la Constitución se refiere, como la primera materia sobre la que «en particular» la ley debe reservar funciones al Consejo, la referente a los nombramientos. Ahora bien el régimen de nombramientos resulta muy variado, en atención a las diversas situaciones que pueden producirse. En forma forzosamente genérica, podrían enumerarse dos tipos de situaciones; los nombramientos de carácter reglado, (tanto resultantes de proceso inicial de selección, como de la promoción dentro de la carrera judicial) y los nombramientos reservados a la competencia discrecional del Consejo. ${ }^{13}$

La Constitución establece expresamente un sistema judicial «de carrera», lo que implica la existencia de una judicatura estructurada como un cuerpo de funcionarios (la Constitución se refiere a «un cuerpo único") dentro del cual se produce una cierta movilidad de sus componentes: la Constitución se refiere también expresamente a los ascensos. La inamovilidad del juez se configura así como una inamovilidad relativa, que incluye la posibilidad de cambios de destino. La configuración de la judicatura como un cuerpo de funcionarios supone la aplicación a los mecanismos de ingreso y ascenso de los principios de mérito y capacidad proclamados en el artículo $103^{\circ}$ de la Constitución como referidos a toda la función pública. Ello, unido a la exigencia constitucional de independencia de los jueces, supone que el régimen de nombramientos sea, con los matices que se señalarán más abajo, un régimen reglado, en que se excluyen decisiones de tipo discrecional.

13 Para un análisis del sistema de nombramientos, ver J. Montero Aroca, Independencia y responsabilidad del juez, Madrid, 1990, pp. 151-168. Del mismo, con otros colaboradores. Derecho jurisdiccional. Parte general. Valencia, 1999, pp. 162-167. 
Así, y por lo que se refiere a los nombramientos resultantes del proceso de selección inicial, la actuación del Consejo se ve forzosamente predeterminada por el resultado de decisiones adoptadas por los órganos técnicos que intervienen en ese proceso, esto es, los tribunales de oposiciones y la escuela judicial en el caso de jueces, y los tribunales encargados de la resolución del concurso para la provisión de magistrados por el «cuarto turno». En este aspecto, el Consejo carece de cualquier viso de discrecionalidad. En lo que se refiere al proceso de selección, la intervención misma del Consejo ha variado notablemente en su aún corta historia. Las sin duda importantes competencias relativas a la determinación del temario de oposiciones, especificación del número de plazas a convocar y fecha de convocatoria, designación de tribunales y dirección de la Escuela Judicial han sido atribuidas en ocasiones al Consejo (así, en el régimen establecido por la Ley del Consejo General del Poder Judicial de 1980, y la reforma de 1994 de la Ley Orgánica del Poder Judicial), en otras al Ministerio de Justicia (Ley Orgánica del Poder Judicial, en su versión de 1985) y finalmente (ę) a ambas instancias conjuntamente (régimen de oposiciones conjuntas a jueces y fiscales introducido por la reforma del año 2000 de la LOPJ).

El sistema de movilidad y promoción dentro de la carrera judicial responde también a criterios fijados por la ley, y que dejan escaso margen a la discrecionalidad. La Ley Orgánica del Poder Judicial trata de evitar que los mecanismos de promoción supongan, real o potencialmente, una amenaza para la independencia judicial. El ascenso de la categoría de juez a la de magistrado se hace depender de criterios objetivos rígidos, como son la antigüedad o la superación de pruebas internas en la carrera judicial (arts. $311^{\circ}-312^{\circ}$ LOPJ). Por lo que se refiere a la provisión de plazas concretas, la Ley Orgánica del Poder Judicial establece como método general el concurso (Art. 326 LOPJ), y como criterio también general (sujeto a considerables matices, sin embargo) para la resolución de esos concursos, el del «mejor puesto en el escalafón» (arts. 329-330 LOPJ). En la práctica ello ha supuesto el establecimiento de la antigüedad en la carrera como un factor decisivo. Se trata de un criterio que sin ninguna duda puede verse sometido a críticas desde la perspectiva de la eficacia de la administración de justicia, y de los incentivos al perfeccionamiento de jueces y magistrados; pero difícilmente podrá negarse que se trata de un criterio objetivo, inmediatamente verificable y que difícilmente puede ser objeto de manipulación. 
Sin embargo, el criterio general, reglado, de provisión de plazas tiene algunas excepciones, que suponen la introducción de criterios políticos, en el sentido de que se deja al órgano que designa (en este caso el Consejo General del Poder Judicial) un amplio margen de apreciación, basado en consideraciones de oportunidad o conveniencia. Estas excepciones se refieren, sobre todo, a dos tipos de plazas judiciales. Por un lado, las referentes a cargo de gobierno en el sistema judicial (Presidentes de Audiencias Provinciales, de Tribunales Superiores de Justicia, de la Audiencia Nacional y sus Salas y de las Salas del Tribunal Supremo), y por otro, las plazas de Magistrado del Tribunal Supremo y de Magistrados de las Salas de lo Civil y Penal de los Tribunales Superiores de justicia. Como puede verse, se trata de un número comparativamente reducido de nombramientos, pero con innegable relevancia. En estos casos, y salvo la exigencia de unos requisitos mínimos iniciales, la Ley Orgánica del Poder Judicial atribuye al Consejo General del Poder Judicial una considerable libertad de acción y los requisitos de antigüedad dejan de ser determinantes al respecto.

¿Qué justificación pueden tener estas excepciones? Por lo que se refiere a las Presidencias de Audiencias, Tribunales y Salas, parece que debe entenderse que, al llevar anejo un componente gubernativo, y no sólo jurisdiccional, es exigible una capacidad específica de gestión y dirección, que difícilmente puede resultar de la mera antigüedad en la carrera. Por otra parte, resulta difícil prever en la ley requisitos directamente encaminados a asegurar la presencia de esa capacidad. Como consecuencia, la Ley Orgánica se remite a la apreciación del Consejo para la selección de las personas más adecuadas para llevar a cabo una tarea de dirección y gestión en los diversos órganos jurisdiccionales.

La justificación de la (relativa) libertad de acción del Consejo es distinta en lo que se refiere a la designación de los Magistrados del Tribunal Supremo y de los Magistrados de las Salas de lo Civil y Penal de los Tribunales Superiores de Justicia. En el primer supuesto, esa justificación residiría en las especiales funciones del Tribunal Supremo, relativas no solamente a la resolución de litigios concretos, sino también a la fijación de la jurisprudencia de los Tribunales a que hace referencia el artículo $161^{\circ} .1$.a) de la Constitución. De nuevo, la capacidad para llevar a cabo esta tarea de índole forzosamente doctrinal no aparece como naturalmente vinculada a la antigüedad; y, en este tipo de posiciones, las ventajas derivadas de ese criterio resultarían supera- 
das por sus posibles inconvenientes. La apreciación de la presencia de las necesarias cualidades queda así en manos del Consejo, siendo también difícil que la ley pudiera establecer (aparte de unos requisitos mínimos de antigüedad) criterios determinantes para el nombramiento, y que asegurasen esa presencia. Y por lo que se refiere a las Salas de lo Civil y Penal de los Tribunales Superiores de Justicia, la justificación de la designación discrecional de sus miembros derivaría de que cumplen funciones equivalentes a las del Tribunal Supremo en lo que se refiere al Derecho civil propio, así como de las competencias que ostentan respecto de personas aforadas. ${ }^{14}$

No han faltado ocasiones en que este conjunto de excepciones al sistema normal de provisión de plazas ha sido objeto de una cierta discusión en foros políticos y académicos. ${ }^{15}$ Por ello, puede resultar conveniente una exposición de algunas características del procedimiento seguido en la provisión de esas plazas, para una mejor comprensión y análisis de los términos en que esa discusión de plantea. $Y$, a este respecto, el mecanismo de provisión, de acuerdo con la actual regulación, sigue siendo el concurso: en otras palabras, es necesario que los candidatos se presenten expresamente, formulando su pretensión de ocupar la plaza, y alegando y documentando los méritos que crean oportunos en apoyo de esa pretensión. Ahora bien (y a diferencia de lo que ocurre en otros ordenamientos, como el italiano, respecto de procedimientos similares) al anunciarse el concurso no se establecen unos baremos objetivos, ni unos criterios que el Consejo se comprometa a seguir. La decisión del Consejo, adoptada en el pleno, se lleva a cabo a partir de una propuesta en terna formulada por la comisión de calificación. La votación es secreta, en dos sentidos: las sesiones del Consejo no son públicas, y los votos de vocales y presidente son votos secretos. La decisión de cada miembro del Consejo se adopta pues sin

14 Por ejemplo, J. Montero Aroca: "La reforma de las Salas de lo Civil y Penal», en: Poder Judicial 24 (1991) p. 105 y ss. También J. Flors Maties: "La Sala de lo Civil y Penal del Tribunal Superior de Justicia. Constitución, composición, competencia y especialidades procesales" en: Poder Judicial y Comunidades Autónomas. Extraordinario de Revista Valenciana d'Estudis Autonomics, 18 (1999) pp. 185-242, especialmente pp. 187-189, con un análisis del polémico significado del Art. 330.3 LOPJ.

15 Ver J.L. Requero: "Nombramientos discrecionales, justicia interina e inspección" en E. Pedraz Penalva, (coord.) El Gobierno de la Justicia. El Consejo General del Poder Judicial, Valladolid, 1996, pp. 143-160. 
control externo alguno, ni siquiera el de la publicidad. Y el nombramiento se lleva a cabo sin motivación de ninguna clase, apareciendo así como un acto de voluntad del Consejo, basado en discusiones y apreciaciones que no se hacen públicas.

\section{El control judicial de las actuaciones del Consejo}

La regulación de los diversos procedimientos de nombramiento de jueces y magistrados constituye un revelador ejemplo de los distintos regímenes jurídicos en los que actúa el Consejo General del Poder Judicial. Por lo que atañe a la gran mayoría de los nombramientos, las exigencias derivadas de los mandatos constitucionales relativos a la independencia del juez y a su integración en un cuerpo estatal único se traducen en un sistema reglado de nombramientos, traslados y promociones, dentro del cual el Consejo General del Poder Judicial actúa como estricto ejecutor de mandatos taxativamente contenidos en la ley. Como consecuencia, no le queda ámbito alguno de discrecionalidad en su actuación, que, en lo que atañe a estos aspectos es íntegramente controlable por los Tribunales. Es aquí aplicable, sin mengua alguna, lo preceptuado en el artículo $143^{\circ} .2$ de la Ley Orgánica del Poder Judicial: "los actos, disposiciones y resoluciones emanados del Pleno serán recurribles en vía contencioso administrativa ante la Sala correspondiente del Tribunal Supremon. Y, de hecho, es ya considerable la jurisprudencia de la Sala Tercera entrando a conocer de decisiones del Consejo relativas al ingreso en la carrera judicial y la movilidad dentro de ella, partiendo del carácter reglado de la actuación del CGPJ en estas materias. ${ }^{16}$

Naturalmente, otra es la cuestión en lo que se refiere a los nombramientos relativos a los puestos en los que el Consejo dispone de un ámbito de actuación "político", i.e. en que caben consideraciones no predeterminables por la ley, incluyendo criterios de conveniencia y oportunidad. En estos casos, a que se hizo arriba referencia, si bien

16 Como ejemplo, y citando sólo algunas resoluciones recientes, valga mencionar las SSTS de 19 de enero de 1996 (jurisdicción de menores), 20 de noviembre de 1997 (plazas de especialistas), 4 de diciembre de 1998 (Magistrados suplentes y jueces sustitutos) o 9 de diciembre de 1999 (Magistrados de Audiencia Provincial) 
ciertamente es aplicable un control jurisdiccional estricto sobre los aspectos reglados del procedimiento, así como sobre el cumplimiento de los requisitos que la ley sí prevé, otra es la situación en lo que se refiere al ámbito de libertad que la ley reserva al Consejo. En efecto, el Tribunal Supremo ha podido reconocer que existe un elemento de discreción en la actuación selectiva respecto de estas plazas, que no puede ser sustituido por una decisión del Tribunal revisor, por cuanto corresponde al Consejo expresar su confianza en la persona selecciona$\mathrm{da}$, confianza que resulta de consideraciones reservadas en exclusiva al Consejo. ${ }^{17}$ Ello no quiere decir, sin embargo ( $y$ frente a lo que en alguna ocasión ha podido entenderse) ${ }^{18}$ que estos puestos sean cargos de confianza del Consejo. Ciertamente ello no es así, por cuanto, en lo que atañe a los magistrados del Tribunal Supremo y de las Salas de lo Civil y Penal de los Tribunales Superiores de Justicia, su nombramiento es irrevocable y permanente (hasta la jubilación, renuncia, o alguna de las demás causas previstas en la ley, que desde luego no incluyen la revocación discrecional por el Consejo). Y, en cuanto a los cargos de gobierno (presidentes de Audiencias, Tribunales Superiores y Salas del Supremo y la Audiencia Nacional) su nombramiento se extiende durante un período determinado, en el que el designado es también inamovible por la voluntad del Consejo.

\section{La extensión de las funciones políticas del Consejo}

El régimen de los nombramientos constituye un ejemplo revelador de la diversa naturaleza de las funciones del Consejo. Un régimen similar

17 Respecto de este tema, y en lo que se refiere a los puestos "de gobierno" es relevante la Sentencia de la Sala Tercera del Tribunal Supremo (Sección 7a) de 30 de noviembre de 1999. Para un comentario de la misma, ver M. Bacigalupo Saggese: «En torno a la motivación de los actos discrecionales emanados de órganos colegiados. ¿Debe el Consejo General del Poder Judicial motivar los nombramientos judiciales de carácter discrecional?» en: Revista Española de Derecho Administrativo 107 (2000) pp. 407-420. En relación con el nombramien to de los Magistrados de las Salas de lo Civil y Penal de los Tribunales Superiores de Justicia, ver la STS (Sala Tercera) de 17 de mayo de 1991.

18 Tal es la interpretación que lleva a cabo Bacigalupo Saggese, en el artículo citado en la nota anterior. En mi opinión (y sin desear formular trabalenguas) llevar a cabo una designación basada en la confianza no convierte dicho cargo en "cargo de confianza". 
al de los nombramientos reglados puede encontrarse en un amplio elenco de actuaciones, que quedan sometidas a los estrictos mandatos legales, y respecto de las cuales el Consejo no dispone de margen alguno de discrecionalidad o de elección entre opciones: y como consecuencia, cabe respecto de estas actuaciones una completa revisión judicial, tanto en cuanto a la forma como en cuanto al fondo de la decisión. Pero, junto a ellas, otro conjunto de actuaciones están sujetas a un régimen similar al aplicable a los nombramientos «libres", de manera que, sin perjuicio de la existencia de elementos reglados en las mismas, le queda al Consejo un margen de libertad para elegir entre las opciones, igualmente válidas, que se le presentan. En realidad, no resulta fácil delimitar con precisión los ámbitos o materias «regladas" $y$ «discrecionales» de la actuación del Consejo, por cuanto, en el ejercicio de cada una de las funciones que corresponden a este órgano cabe distinguir fases y actuaciones sometidas a régimen distinto. Como ejemplo, en el proceso de selección, corresponde al Consejo decidir el número de plazas que saca a oposición y le corresponde, (o, al menos, correspondía hasta la reforma de la LOPJ en diciembre de 2000) establecer el programa de oposiciones adoptando al respecto una decisión libre que, en el sentido arriba apuntado, no cabe designar sino como política; pero, dentro del mismo proceso de selección, estaba y está sujeto a las normas legales y reglamentarias en cuanto a la designación de tribunales y al procedimiento de examen. ${ }^{19}$ Por otra parte, si bien debe atenerse, en cuanto a los candidatos seleccionados, a los resultados de las oposiciones que establezcan los tribunales examinadores, corresponde libremente al Consejo establecer el programa y designar al profesorado de la Escuela Judicial. Como ejemplo adicional, aun cuando en materia disciplinaria, el Consejo debe atenerse escrupulosamente al principio de legalidad sancionadora, en lo que se refiere a una actividad previa, como es la inspectora, el Consejo debe y puede fijar libremente los criterios a seguir. Los aspectos reglados y políticos de la actividad de Consejo se encuentran así entremezclados, como por otra parte es típico en relación con cualquier órgano de gobierno. ${ }^{20}$ La presencia de

19 Como ejemplo de control judicial sobre elementos reglados en las oposiciones, ver STS, Sala Tercera, de 1 de julio de 1995 (nombramiento de vocales de Tribunales).

20 Incluso en el proceso de nombramientos «libres» de cargos judiciales: ver, por ejemplo, la STS (Sala Tercera) de 31 de mayo de 1995 sobre aspectos reglados de esos nombramientos. 
aspectos reglados en su actuación no empece pues a que el Consejo se defina como un órgano político.

Ello naturalmente plantea una cuestión ineludible. La dimensión libre de la acción política, la posibilidad de seleccionar discrecionalmente una de entre las opciones presentes implica necesariamente la responsabilidad del actor; esto es, la posibilidad de que esa actuación sea evaluada en términos de acierto o error, de éxito o fracaso, y de que se impute ese éxito o fracaso directamente al actor político, y a su mayor o menor capacidad o habilidad. El juez no es responsable, en este sentido, de la ley que aplica, puesto que no tiene elección ninguna al respecto; por lo tanto no pueden imputársele los resultados, buenos o malos, que deriven de la aplicación de la ley. Pero al Consejo sí pueden imputársele los resultados de las acciones que lleve a cabo, y por lo tanto será responsable de la política que adopte, al ser una política libremente decidida. Responsabilidad, sin embargo, que no puede ser ya (como sí lo es respecto de los aspectos reglados de su actuación) meramente jurídica y exigible ante los Tribunales, puesto que, por definición, deriva de una acción «libre».

En un sistema constitucional y democrático, no cabe en principio que haya poderes cuya actuación, en cuanto no sea mera ejecución de las decisiones de otros, no esté sujeta a control y exenta de responsabilidad. No cabe así una acción política o de gobierno incontrolada e irresponsable, lo que da lugar a la cuestión de cómo se efectúa ese control y cómo se exige esa responsabilidad. Esta cuestión no afecta únicamente al Consejo General del Poder Judicial, sino que se plantea también en relación con otros poderes del Estado que quedan fuera de la normal relación de control y confianza existente en un régimen parlamentario entre Gobierno y Cámaras. Como ejemplo, pueden citarse los problemas de este tipo que se suscitan en relación con órganos como el Defensor del Pueblo, el Fiscal General del Estado, o las cada vez más numerosas «administraciones independientes». Así y todo, la cuestión, respecto del Consejo General del Poder Judicial, presenta matices propios.

En efecto, la misma existencia de la institución deriva de la voluntad de asegurar la independencia judicial, de manera que elementos decisivos en la configuración de poder judicial queden fuera de la posible influencia de otros poderes del Estado, no sólo y sobre todo, del ejecutivo, sino también del legislativo, en cuanto integrado por representantes integrados en grupos alineados según su apoyo u oposición al Gobierno. Ahora bien, la introducción 
de mecanismos de control y de exigencia de responsabilidad referidos al Consejo General del Poder Judicial por parte de esos poderes podría con toda evidencia repercutir en la efectiva independencia del órgano, y por tanto, e indirectamente, en la misma independencia de los jueces y magistrados integrantes del poder judicial que el Consejo debe garantizar. Es por ello comprensible que la Constitución y la Ley Orgánica del Poder Judicial hayan sido parcas en la previsión de elementos de control de la actividad del Consejo, y hayan excluido cualquier mecanismo de exigencia de responsabilidad política del Consejo y de sus miembros. En cuanto a los mecanismos de control, se reducen la posible comparecencia de los miembros del Consejo ante el Pleno o las Comisiones de las Cámaras, como resulta del Art. $76^{\circ} .2$ de la Constitución, y a la presentación de la Memoria y del Plan de Necesidades previstos en el Art. $109^{\circ} .1$ y 2 de la Ley Orgánica del Poder Judicial. En cuanto a la exigencia de responsabilidad política, y pese a algunas sugerencias en ese sentido, la LOPJ no prevé fórmula de ningún tipo para instrumentar el mecanismo típico al respecto, esto es, la remoción, por el Gobierno o el Parlamento, de alguno o todos los miembros del Consejo.

Esto no significa, desde luego, que de la acción política de éste no se derive responsabilidad política de ningún tipo; pues tal responsabilidad se traslada (como en otros supuestos) a los que designaron a los titulares del órgano; en este caso, y de acuerdo con la Ley Orgánica del Poder Judicial, a las Cámaras. La responsabilidad política del Consejo es pues indirecta, y será exigida en su momento por los electores a los representantes parlamentarios que designaron a los miembros del Consejo. Será pues, en último término, el electorado, con ocasión de las elecciones a Cortes Generales quien se pronunciará por esta tortuosa vía sobre la adecuación política de la actuación de gobierno del Consejo.

Ciertamente, no puede considerarse que éstas sean fórmulas muy efectivas para hacer valer los principios de control parlamentario y de exigencia de responsabilidad a los poderes públicos. Pero, si quiere mantenerse el principio de independencia judicial, y respetar la finalidad con que el Consejo fue creado, parece difícil introducir formas más estrictas de control, o de exigencia de responsabilidad. En cualquier caso, al menos dos consecuencias pueden extraerse inicialmente de las consideraciones precedentes:

a) $\mathrm{Al}$ ser forzosamente reducidas las posibilidades de un control político sobre el Consejo, y de exigencia de responsabilidad política del mismo, pese a corresponder constitucionalmente al Consejo General del 
Poder Judicial el ejercicio de potestades de gobierno, es decir, de potestades políticas, y por ello no completamente fiscalizables por los Tribunales, el principio general de responsabilidad de los poderes públicos, inherente a un sistema constitucional exigiría que las materias atribuidas a esa potestad de gobierno se atuvieran estrictamente a los límites constitucionales. La extensión de las competencias del Consejo (que, como se dijo, no aparecen enumeradas en la Constitución) representaría también la extensión de un ámbito de materias exentas de un satisfactorio control parlamentario, y de mecanismos de exigencia de responsabilidad. Si la independencia judicial exige una atenuación de esos principios, tal atenuación debería ser la menor posible. Obviamente ello supone (y este extremo exigiría un tratamiento más amplio del que aquí es posible) una presunción inicial en contra de la legitimidad democrática de la ampliación de las competencias del Consejo.

b) Como segunda consecuencia, dada la parquedad de instrumentos de exigencia de responsabilidad de la actuación política del Consejo, parece que esos instrumentos, dentro de los mandatos constitucionales, debieran ser potenciados al máximo. Excluida la responsabilidad directa de los miembros del Consejo, y sustituida por la responsabilidad ante el electorado de los representantes que los designaron, la posibilidad y alcance de esta forma de exigencia de responsabilidad debería extenderse hasta donde la Constitución lo permitiera. Desde esta perspectiva, ello supone una preferencia por la elección parlamentaria de todos los vocales del Consejo, a efectos de hacer posible una exigencia -siquiera indirecta- de responsabilidad por la acción de todos ellos. La elección de parte de los vocales por instancias que no estuvieran sujetas al juicio del electorado haría desaparecer, obviamente, cualquier posible exigencia de responsabilidad respecto de los mismos, y por tanto, cualquier posibilidad de que el sujeto último de la soberanía expresara un juicio, positivo o negativo, sobre la actuación de un órgano encargado de una tarea política, como es, según se ha argumentado, el gobierno del poder judicial. ${ }^{21}$

21 En contra, y para una crítica del sistema de elección parlamentaria de los vocales del Consejo, exponiendo el punto de vista de la Asociación Profesional de la Magistratura, ver J.L. Requero Ibáñez: El Gobierno Judicial y el Consejo General del Poder Judicial, publicado por la Fundación para el Análisis y los Estudios Sociales, Madrid, 1996 , p. 31 y ss. 